\title{
Suicidality in pre-adolescence and early adulthood is associated with psychosocial and psychiatric problems in young adulthood
}

Steinhausen HC, Winkler Metzke CW. The impact of suicidal ideation in preadolescence, adolescence, and young adulthood on psychosocial functioning and psychopathology in young adulthood. Acta Psychiatr Scand 2004;1 10:438-45.

Do episodes of suicidal behaviour or thoughts in pre-adolescents and mid-adolescents have the same psychosocial and psychiatric outcomes in early adulthood as enduring or current suicidality?

\section{METHODS}

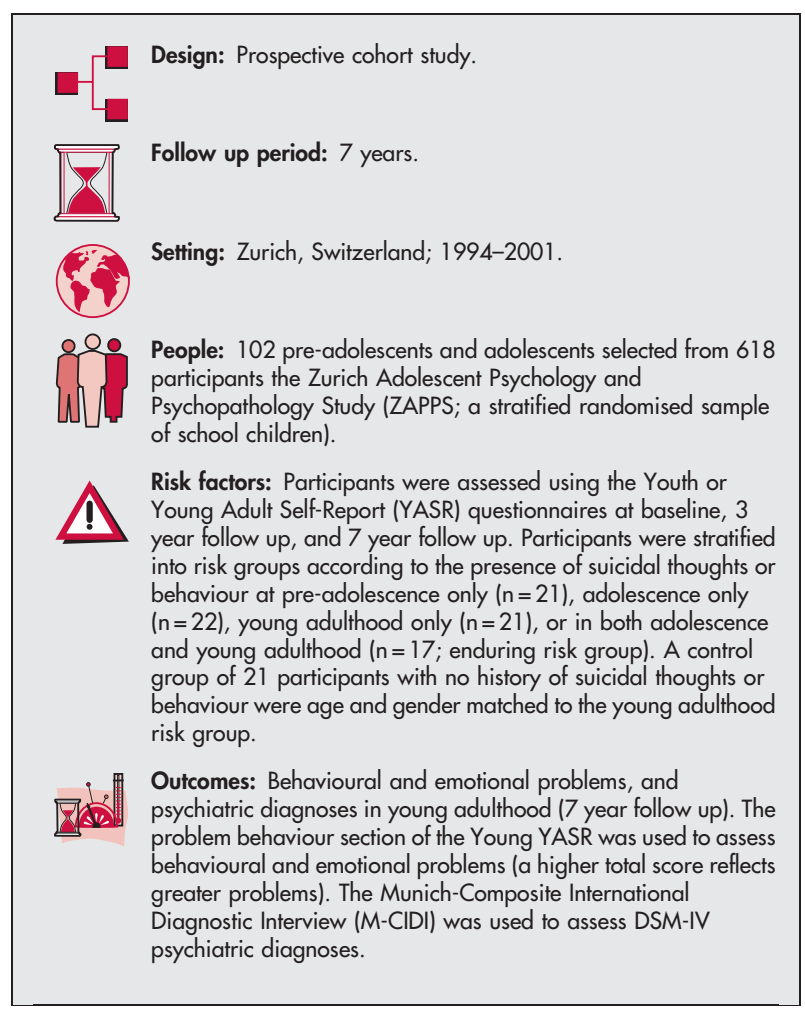

\section{MAIN RESULTS}

Young adults with current or enduring suicidal thoughts and behaviour had the greatest behavioural and emotional problems (total YASR score: 63.96 enduring risk group $v 60.19$ young adult risk group $v 37.81$ adolescent risk group $v 31.82$ pre-adolescent risk group $v 21.34$ control group; $\mathrm{p} \leqslant 0.001$ ). Psychiatric disorders were common in all young adults who had experienced suicidal thoughts and behaviour, but were especially so in those who had pre-adolescent, current or enduring suicidal thoughts and behaviour (AR for any DSM-IV psychiatric disorder: pre-adolescent risk group 92\%; adolescent risk group 59\%; young adult risk group $86 \%$; enduring risk group $88 \%$; control group $10 \% ; \mathrm{p}<0.001$ ). The most common psychiatric disorders were substance abuse $(48 \%)$, phobias $(41 \%)$, depressive disorders $(35 \%)$, and somatoform disorders $(21 \%)$.

\section{CONCLUSIONS}

Suicidal thoughts or behaviour from pre-adolescence to young adulthood (whether episodic or enduring) is associated with risk of psychosocial and psychiatric problems in young adults, especially if suicidality occurs before adolescence, in early adulthood, or is enduring.

For correspondence: Professor Steinhausen, Department of Child and Adolescent Psychiatry, University of Zurich, Neum_nsterallee 9, Postfach, CH-8032 Zurich, Switzerland; steinh@kipd.unizh.ch

Sources of funding: Swiss National Science Foundation.

\section{Commentary}

S teinhausen and Winkler Metzke clearly demonstrate that young people reporting suicidal ideation remain at increased risk in a large number of behavioural domains. This research adds to the evidence from longitudinal studies that suicidal ideation and behaviours, including attempted suicide, are frequently precursors of longer term difficulties. ${ }^{1-6}$ These difficulties span an array of problems including suicidal behaviour, psychiatric morbidity, mortality from suicide and other causes, and psychosocial problems such as relationship problems, legal charges, imprisonment, and social welfare dependence.

The important issue raised here concerns the types of programme and services required to address the needs of young people with suicidal ideation. These have included family oriented therapies, problem solving training, cognitive behavioural therapy (CBT), dialectical behavioural therapy, pharmacotherapy, and training general practitioners to better recognise and treat suicidality in young people..$^{7-12}$ However, most of these have not been rigorously evaluated. One exception is the TADS study, a randomised controlled trial (RCT) of 439 adolescents (12-17 years) assigned to one of three treatments: 12 weeks of fluoxetine (10$40 \mathrm{mg} /$ day) or CBT or CBT with fluoxetine. The authors concluded that CBT with fluoxetine offered the most favourable trade-off between benefit and risk for adolescents with major depressive disorder.

At this stage further experimental work is needed to build on the basic epidemiology in this area and to assess, using RCT methodology, the extent to which a range of interventions in suicidal young people mitigates longer term risk.

Annette Beautrais, $\mathrm{PhD}$

Principal Investigator, Canterbury Suicide Project, Christchurch School of Medicine and Health Sciences, New Zealand

1 Fergusson DM, Horwood $\mathrm{U}$, Ridder EM, et al. Sub-threshold depression in adolescence and mental health outcomes in adulthood. Arch Gen Psychiatry 2005;62:66-72.

2 Goldney RD, Smith S, Winfield AH, et al. Suicidal ideation: Its enduring nature and associated morbidity. Acta Psychiatr Scand 1991;83:115-20.

3 Hawton K, Zahl D, Weatherall R. Suicide following deliberate self-harm: Long-term follow-up of patients who presented to a general hospital. $\mathrm{Br} J$ Psychiatry 2003;182:537-42.

4 Henriques GR, Brown GK, Berk MS, et al. Marked increases in psychopathology found in a 30-year cohort comparison of suicide attempters. Psychol Med 2004;34:833-41.

5 Hulten A, Jiang GX, Wasserman D, et al. Repetition of attempted suicide among teenagers in Europe: frequency, timing and risk factors. Eur Child Adolesc Psychiatry 2001:10:161-9.

6 Zahl DL, Hawton K. Repetition of deliberate self-harm and subsequent suicide risk: Long-term follow-up study of 11583 patients. Br J Psychiatry 2004; 185:70-5

7 Carris MJ, Sheeber L, Howe S. Family rigidity, adolescent problem-solving deficits, and suicidal ideation: a mediational model. J Adolesc 1998;2:45972.

8 Katz LY, Cox BJ, Gunasekara S, et al. Feasibility of dialectical behavior therapy for suicidal adolescent inpatients. J Am Acad Child Adolesc Psychiatry 2004;43:276-82.

9 March J, Silva S, Petrycki S, et al. Fluoxetine, cognitive-behavioral therapy, and their combination for adolescents with depression: Treatment for Adolescents With Depression Study (TADS) randomized controlled trial. JAMA 2004;292:807-20.

10 Olson DH. Circumplex model of marital and family systems. In: Walsh F, ed. Normal Family Processes. New York: Guilford Press, 1993:104-37.

11 Pfaff JJ, Acres JG, McKelvey RS. Training general practitioners to recognise and respond to psychological distress and suicidal ideation in young people. Med J Aust 2001;174:222-6.

12 Shaffer D, Pfeffer CR, Bernet W, et al. Practice parameters for the assessment and treatment of children and adolescents with suicidal behavior. J Am Acad Child Adolesc Psychiatry 2001;40:24S-51S. 